\title{
Occurrence and Distribution of Mating Types of Pseudoperonospora cubensis in the United States
}

\author{
Anna Thomas, Ignazio Carbone, Yigal Cohen, and Peter S. Ojiambo
}

First, second, and fourth authors: Center for Integrated Fungal Research, Department of Entomology and Plant Pathology, North Carolina State University, Raleigh 27695; and third author: Faculty of Life Sciences, Bar-Ilan University, Ramat Gan 52100, Israel. Accepted for publication 10 November 2016.

\begin{abstract}
During the past two decades, a resurgence of cucurbit downy mildew has occurred around the world, resulting in severe disease epidemics. In the United States, resurgence of the disease occurred in 2004 and several hypotheses, including introduction of a new genetic recombinant or pathotype of the pathogen, have been suggested as potential causes for this resurgence. Occurrence and distribution of mating types of Pseudoperonospora cubensis in the United States were investigated using 40 isolates collected from cucurbits across 11 states from 2005 to 2013. Pairing of unknown isolates with known mating-type tester strains on detached leaves of cantaloupe or cucumber resulted in oospore formation 8 to 10 days after inoculation. Isolates differed in their ability to form oospores across all coinoculation pairings, with oospore numbers ranging from 280 to 1,000 oospores $/ \mathrm{cm}^{2}$ of leaf tissue. Oospores were hyaline to golden-yellow, spherical, and approximately $36 \mu \mathrm{m}$ in diameter. Of the 40 isolates tested, 24 were found to be of the A1 mating type, while 16 were of the A2 mating type. Mating type was significantly $(P<0.0001)$ associated with host type, whereby all isolates

collected from cucumber were of the A1 mating type, while isolates from squash and watermelon were of the A2 mating type. Similarly, mating type was significantly $(P=0.0287)$ associated with geographical region, where isolates from northern-tier states of Michigan, New Jersey, New York, and Ohio were all A1, while isolates belonging to either A1 or A2 mating type were present in equal proportions in southern-tier states of Alabama, Florida, Georgia, North Carolina, South Carolina, and Texas. Viability assays showed that oospores were viable and, on average, approximately $40 \%$ of the oospores produced were viable as determined by the plasmolysis method. This study showed that A1 and A2 mating types of $P$. cubensis are present and the pathogen could potentially reproduce sexually in cucurbits within the United States. In addition, the production of viable oospores reported in this study suggests that oospores could have an important role in the biology of $P$. cubensis and could potentially influence the epidemiology of cucurbit downy mildew in the United States.
\end{abstract}

Pseudoperonospora cubensis is an obligate, biotrophic oomycete that causes cucurbit downy mildew (CDM), a disease that is widely recognized as the most important foliar disease of cucurbits worldwide (Lebeda and Cohen 2011). The pathogen is widely distributed in temperate and semiarid regions and has a wide host range that includes both wild and cultivated cucurbits (Lebeda 1992). Approximately 60 species of cucurbits have been reported as hosts of $P$. cubensis and the most economically important host crops include cucumber, cantaloupe, watermelon, pumpkin, and squashes (Lebeda 1992). In the United States, cucurbits are grown primarily in the eastern half of the country and in California, and 383,630 acres were harvested in 2015 , with a value of $\$ 1.4$ billion (Anonymous 2016). Due to the availability of resistant cultivars deployed in the 1960s, downy mildew on cucumber was of minor concern in the United States, requiring only very few fungicide applications to control the disease. This longstanding source of resistance in cucumber was the plant introduction (PI) accession PI 197087 (Barnes and Epps 1954). However, resistance from PI 197087 was overcome after 40 years and a resurgence of CDM was observed in 2004, leading to severe disease epidemics in the eastern United States in the 2004 and 2005 growing seasons, with significant or total crop loss in many fields (Holmes et al. 2006). Around this time period, new aggressive pathotypes capable of attacking Cucurbita spp. were also reported in Israel (Cohen et al. 2003) and parts of Europe (Cappelli et al. 2003; Lebeda and Urban 2004). Since 2004, CDM now occurs annually in the United States and application of fungicides is required to avoid significant crop losses.

There have been considerable efforts to establish possible causes for the resurgence of CDM in the United States (Holmes et al. 2015;

Corresponding author: P. S. Ojiambo; E-mail address: pojiamb@ncsu.edu

(C) 2017 The American Phytopathological Society
Ojiambo et al. 2015; Quesada-Ocampo et al. 2012) and other parts of the world (Cohen et al. 2015; Kitner et al. 2015; Lebeda et al. 2013). It has been suggested that the resurgence of CDM in the United States could have been due to introduction of a new lineage or pathotype or even a new species of the pathogen (Colucci 2008; Runge et al. 2011). It has also been hypothesized that cryptic lineages within $P$. cubensis might be able to hybridize, resulting in an emergence of hypervirulent strains (Runge et al. 2011). New genetic recombinants as a result of sexual reproduction have also been suspected as a possible cause for the resurgence in Israel (Cohen and Rubin 2012). Studies conducted in Israel have shown that $P$. cubensis is heterothallic and has two mating types, A1 and A2 (Cohen and Rubin 2012). Thus, sexual reproduction can occur when mycelia of both mating types grow together in close proximity on the same leaf. The potential for sexual recombination has two important implications for the P. cubensis-CDM pathosystem. First, sexual reproduction involves production of thick-walled oospores that can survive in the soil and remain viable for 10 months and still cause infection (Zhang et al. 2012). Formation of oospores can create opportunities for $P$. cubensis to overwinter in areas where cucurbits are unable to survive due to harsh winters. In such areas, oospores can survive in the soil or plant debris and, thereby, serve as an initial source of inoculum for early onset of disease epidemics. Second, new genetic combinations from sexual reproduction can create opportunities for the emergence of unusually fit or aggressive offspring. $P$. cubensis also reproduces asexually via aerially borne sporangia. Thus, sexual reproduction will greatly increase the pathogen's evolutionary potential and ability to overcome host resistance (McDonald and Linde 2002).

Oospore production in $P$. cubensis is rare and reports on oospore formation have mainly been from Asia and Europe (Bains et al. 1977; Bedlan 1989; Hiura and Kawada 1933; Palti and Cohen 
1980). In the United States, the quest for oospores as evidence for sexual reproduction can be traced back to 1889 , when the pathogen was first reported in the country (Halsted 1889). Halsted (1889) did not observe formation of oospores and the search efforts were initiated again by Foster (1920) following the first report on oospore formation by Rostowzew (1903) in Russia. Doran (1932) continued the search for oospores in the United States in infected leaves of cucumber inoculated with leaf debris and soil suspensions from locations where cucurbits were grown. Doran (1932) also failed to recover oospores in his study. Renewed efforts for the search of oospores in the United States were initiated again following the resurgence of the disease in 2004 but none of these efforts were successful in recovering oospores in nature or generating oospores under laboratory conditions (Cohen et al. 2015; Holmes et al. 2015).

In the United States, $P$. cubensis is widely thought to survive in areas that experience mild winters along the Gulf of Mexico and in southern Florida and Texas. Annual introduction of initial inoculum from these overwintering sources assumes that oospores are not present in cucurbit fields in more northern latitudes. In a study on the spatio-temporal aspects of CDM using reports on disease outbreaks, up to $5 \%$ of reported disease cases were found to be inconsistent with the annual northward advance of the epidemic wave front in the eastern United States (Ojiambo and Holmes 2011). Although this inconsistency in disease spread was very low, it may suggest the existence of other potential but undocumented sources of initial inoculum that may be influencing the initiation of epidemics. Such potential sources of initial inoculum could include oospores that have not yet been detected in cucurbit fields or greenhouses. The potential impact of sexual reproduction and oospores on the epidemiology of CDM and diversity of the pathogen motivated our investigation of this aspect of the biology of P. cubensis within the pathogen populations in the United States. The specific objectives of this study were to (i) establish the existence and distribution of A1 and A2 mating types of P. cubensis in the United States, (ii) determine the production of oospores in coinoculation of isolates of the two mating types in the United States, and (iii) determine the viability of oospores and their infectivity on different cucurbit host types. Preliminary findings on some aspects of this present work have been published elsewhere (Thomas et al. 2013).

\section{MATERIALS AND METHODS}

Collection and maintenance of isolates. In total, 40 singlelesion isolates obtained from field samples collected from different cucurbit host types, including cucumber, cantaloupe, watermelon, giant pumpkin, butternut squash, and acorn squash, were used in this study. These isolates were collected from cucurbit hosts in California and 10 other states in the eastern United States (Table 1). Most of these isolates were collected between 2004 and 2014. In addition, an isolate of $P$. cubensis, Pc1982, isolated from cantaloupe in South Carolina in 1982, was included in the study. Isolate Pc1982 was previously stored at $-80^{\circ} \mathrm{C}$ and was maintained on cantaloupe by periodic reinoculation of detached leaves.

Field samples of infected cucurbit leaves were collected through the CDM ipmPIPE disease monitoring network and transported to the Plant Pathology laboratory at North Carolina State University in

TABLE 1. Source and description of Pseudoperonospora cubensis isolates collected from cucurbits to determine the mating type structure of the population in the eastern United States

\begin{tabular}{|c|c|c|c|c|c|}
\hline Isolate & Year & State & County & Host & Mating type \\
\hline Pc1982 & 1987 & South Carolina & Charleston & Cantaloupe & A2 \\
\hline 05A1 & 2005 & Michigan & Oceana & Cucumber & A1 \\
\hline 05A2 & 2005 & Michigan & Oceana & Cucumber & A1 \\
\hline $05 \mathrm{~F} 1$ & 2005 & North Carolina & Johnston & Acorn squash & $\mathrm{A} 2$ \\
\hline 07B1 & 2007 & North Carolina & Sampson & Cantaloupe & A2 \\
\hline 08A1 & 2008 & California & Salinas & Cucumber & A1 \\
\hline 08F1 & 2008 & Georgia & Tift & Acorn squash & $\mathrm{A} 2$ \\
\hline A12 & 2008 & Florida & St. Johns & Cucumber & A1 \\
\hline 08D1 & 2008 & North Carolina & Johnston & Butternut squash & $\mathrm{A} 2$ \\
\hline $08 \mathrm{C} 1$ & 2008 & New York & Suffolk & Giant Pumpkin & A1 \\
\hline D3 & 2012 & South Carolina & Charleston & Butternut squash & A2 \\
\hline A11 & 2012 & North Carolina & Johnston & Cucumber & A1 \\
\hline 2013A1 & 2013 & Florida & Miami-Dade & Cucumber & A1 \\
\hline 2013A2 & 2013 & Florida & Collier & Cucumber & A1 \\
\hline $2013 \mathrm{~A} 3$ & 2013 & Georgia & Worth & Cucumber & A1 \\
\hline $2013 \mathrm{~A} 4$ & 2013 & Florida & Hillsborough & Cucumber & A1 \\
\hline 2013A5 & 2013 & North Carolina & Wayne & Cucumber & A1 \\
\hline $2013 \mathrm{~A} 7$ & 2013 & Georgia & Sparks & Cucumber & A1 \\
\hline $2013 \mathrm{~A} 9$ & 2013 & North Carolina & Johnston & Cucumber & A1 \\
\hline 2013A10 & 2013 & South Carolina & Charleston & Cucumber & A1 \\
\hline 2013A11 & 2013 & South Carolina & Charleston & Cucumber & A1 \\
\hline 2013A14 & 2013 & North Carolina & Hertford & Cucumber & A1 \\
\hline 2013A15 & 2013 & Alabama & Macon & Cucumber & A1 \\
\hline 2013A16 & 2013 & North Carolina & Edgecombe & Cucumber & A1 \\
\hline 2013A17 & 2013 & North Carolina & Wake & Cucumber & A1 \\
\hline 2013A18 & 2013 & New Jersey & Salem & Cucumber & A1 \\
\hline 2013A19 & 2013 & Ohio & Sandusky & Cucumber & A1 \\
\hline 2013A20 & 2013 & Ohio & Medina & Cucumber & A1 \\
\hline 2013C3 & 2013 & North Carolina & Johnston & Giant Pumpkin & A1 \\
\hline 2013B17 & 2013 & New York & Ontario & Cantaloupe & A1 \\
\hline 2013B1 & 2013 & Florida & Hillsborough & Cantaloupe & $\mathrm{A} 2$ \\
\hline 2013E1 & 2013 & Florida & Collier & Watermelon & A2 \\
\hline 2013E2 & 2013 & Texas & Hidalgo & Watermelon & $\mathrm{A} 2$ \\
\hline $2013 \mathrm{~F} 1$ & 2013 & Florida & Collier & Acorn squash & A2 \\
\hline $2013 F 2$ & 2013 & South Carolina & Charleston & Acorn squash & $\mathrm{A} 2$ \\
\hline 2013D1 & 2013 & Florida & Miami-Dade & Butternut squash & $\mathrm{A} 2$ \\
\hline 2013D2 & 2013 & Florida & Hillsborough & Butternut squash & $\mathrm{A} 2$ \\
\hline 2013D3 & 2013 & South Carolina & Charleston & Butternut squash & A2 \\
\hline 2013D4 & 2013 & North Carolina & Johnston & Butternut squash & $\mathrm{A} 2$ \\
\hline 2013D6 & 2013 & Alabama & Escambia & Butternut squash & A2 \\
\hline
\end{tabular}


Raleigh. Samples were carefully examined and leaves of samples with discrete single lesions were subsequently maintained on their respective hosts as single-lesion isolates. Samples without discrete single lesions were processed further to generate single-lesion isolates. Briefly, sporangia were washed off the leaves using a Preval sprayer (Complete Unit 267; Precision Valve Corporation) and used to inoculate respective whole host plants at concentrations of approximately $1 \times 10^{4}$ sporangia/ml. Inoculated host plants were bagged with a polythene bag and placed in a growth chamber at $18^{\circ} \mathrm{C}$ under dark condition for $24 \mathrm{~h}$. Plants were unbagged after $24 \mathrm{~h}$ and incubated at a regime of 21 and $18^{\circ} \mathrm{C}$ (day and night, respectively), with a photoperiod of light for $12 \mathrm{~h} /$ day. Plants were examined daily for the development of symptoms and, when discrete single lesions became apparent, plants were bagged again and were kept under dark conditions for $24 \mathrm{~h}$ to stimulate sporangia production. Individual lesions were subsequently cut out carefully and used to inoculate respective host plants to multiply sporangia of each isolate. All the isolates were maintained in the laboratory by propagation on their respective host plants using detached leaves until they were ready for use in the subsequent experiments. To propagate the isolates, the abaxial sides of the first or second leaves from respective host plants were placed on sterile moist paper towels in clear acrylic boxes, and the adaxial side was inoculated with a sporangial suspension at approximately $2 \times 10^{4}$ sporangia/ml and incubated in a growth chamber at 21 and $18^{\circ} \mathrm{C}$ (day and night, respectively), with a photoperiod of light for $12 \mathrm{~h} /$ day.

Mating type determination and oospore production. The mating type of individual isolates was determined by pairing, in equal proportions, sporangia of an isolate with sporangia of a tester strain with a known mating type, as described by Cohen and Rubin (2012). In this study, two tester strains were used: an A2 isolate originally isolated from butternut squash in Israel and an A1 isolate (A11) that was originally isolated from cucumber in North Carolina in 2012. Coinoculation of these two tester strains resulted in oospore production. The two tester strains were also maintained on the respective hosts throughout the entire study, as described above.

To determine the mating type of each isolate, sporangial suspensions $\left(2 \times 10^{4}\right.$ spores $\left./ \mathrm{ml}\right)$ of the tester and unknown isolate were mixed together in equal proportion $(1: 1[\mathrm{vol} / \mathrm{vol}])$ and the resultant suspension was used to inoculate detached first true leaves of cantaloupe ('Ananas') or cucumber ('Straight Eight') plants. Cantaloupe and cucumber have been reported as favorable hosts to support production of oospores (Cohen and Rubin 2012). Plants were grown in the greenhouse periodically to ensure a steady supply of the first true leaves that were used in the assay. The adaxial side of the detached leaves was placed on moist paper towels in clear acrylic boxes and the abaxial side of the leaf was spot inoculated on at least 20 different spots with $10 \mu \mathrm{l}$ of the sporangial mixture. Inoculated leaves were then incubated in a growth chamber at $21^{\circ} \mathrm{C}$ under a cycle of $12 \mathrm{~h}$ of light and $12 \mathrm{~h}$ of darkness. At 7 to 10 days postinoculation, leaf discs measuring $11 \mathrm{~mm}$ in diameter were cut from infected leaves and clarified for $24 \mathrm{~h}$ in ethyl alcohol-acetic acid solution (3:1 [ $\mathrm{vol} / \mathrm{vol}])$. Clarified leaf discs were washed three times in deionized water and then examined under a compound microscope $(\times 100$ magnification) for the presence of oospores. Unknown isolates were designated as either $\mathrm{A} 1$ or $\mathrm{A} 2$ if oospores were produced when coinoculated with the A2 or A1 tester strain, respectively. Appropriate crosses were also conducted as internal controls for oospore production using specific isolate-tester combinations.

Viability of oospores. The standard 3-(4,5-dimethylthiazol-2yl)-2,5-diphenyltetrazolium bromide (MTT) test (Sutherland and Cohen 1983) was used to determine the viability of oospores produced from crosses conducted in this study. Oospore viability was also evaluated using the plasmolysis method (Jiang and Erwin 1990) because the MTT test has been reported to be unstable and inconsistent with high rates of false positives (Etxeberria et al. 2011; Ribeiro et al. 1971). In both tests, an oospore suspension to evaluate viability was prepared by homogenizing leaves inoculated with both mating types of $P$. cubensis in $10 \mathrm{ml}$ (per leaf) of sterile distilled water. To ensure consistency in the observed results, assays of oospore viability were repeated at least once.

Viability of oospores using the MTT test was determined as described by Sutherland and Cohen (1983). Briefly, $500 \mu \mathrm{l}$ of the prepared oospore suspension was mixed with an equal volume of $0.1 \%$ MTT stain (Sigma-Aldrich). The suspension containing a mixture of MTT and oospores was then incubated at $35^{\circ} \mathrm{C}$ for $48 \mathrm{~h}$. Thereafter, a droplet of the incubated suspension was dispensed on a glass slide with a cover slip and examined under a compound microscope ( $\times 200$ magnification) for color reaction. In total, 100 oospores were sequentially examined for color reaction as follows: oospores that stained red to rose were considered to be viable dormant, blue were viable activated (pregermination phase), and black and unstained oospores were considered nonviable (Sutherland and Cohen 1983).

To assess oospore viability using the plasmolysis method, $50 \mu \mathrm{l}$ of oospore suspension was first centrifuged for $1 \mathrm{~min}$ at 13,000 rpm. The supernatant was discarded, the resultant pellet was resuspended in $50 \mu \mathrm{l}$ of $4 \mathrm{M} \mathrm{NaCl}$ solution, and the mixture was incubated at room temperature for $45 \mathrm{~min}$. In total, 100 oospores were then observed microscopically for plasmolysis and classified as either viable (i.e., plasmolized) or nonviable (i.e., nonplasmolized). Oospores that are viable have their cytoplasm contracted to form a ball-like structure, while nonviable oospores do not plasmolize because they lack the differential permeability of their cellular membranes (Jiang and Erwin 1990).

Infectivity of oospores. Oospore suspension used to inoculate cucurbit hosts to determine the ability of oospores to cause infection was prepared as described above. Vegetative structures of $P$. cubensis were differentially killed by exposing the homogenized suspension to two cycles of drying and wetting, as described by Rubin and Cohen (2006). Briefly, 5-ml aliquots of the homogenized inoculum suspension were pipetted into 9 -cm petri dishes; then, dishes without lids were placed in the incubator at $26^{\circ} \mathrm{C}$ for $12 \mathrm{~h}$ to allow the liquid homogenate to dry up. Thereafter, $5 \mathrm{ml}$ of water was added to each dish, and the homogenized suspensions were resuspended in the water with the aid of a clean spatula and dried again for $12 \mathrm{~h}$. The dry homogenates were finally resuspended in $3 \mathrm{ml}$ of sterile distilled water and used to spot inoculate adaxial sides of detached leaves $(20 \mu \mathrm{l} / \mathrm{spot})$ of five cucurbit host types, as described above. Inoculated leaves were incubated in a growth chamber at $21^{\circ} \mathrm{C}$ under a cycle of $12 \mathrm{~h}$ of light and $12 \mathrm{~h}$ of darkness for 21 days for formation of sporulating lesions.

Mating type and host specificity. A set of six randomly selected $P$. cubensis isolates belonging to A1 and A2 mating types (three isolates each) originally isolated from diverse cucurbit host types from six different states (Table 2) were tested for their compatibility on a set of eight differential host types. Plants of the host differential set that included Cucumis sativus, C. melo reticulatus, C. melo conomon, Citrullus lanatus, Cucurbita spp. (acorn squash and butternut squash), Luffa cylindrica, and Lagenaria siceraria were grown in the greenhouse to the third-true-leaf stage, as described above. For each host, first and second true leaves were placed with the adaxial side on moist paper towels in clear acrylic boxes and spray inoculated with a sporangial suspension of an A1 or A2 isolate at a concentration of $5 \times 10^{3}$ sporangia/ml. Inoculated leaves were then incubated in a growth chamber at 21 and $18^{\circ} \mathrm{C}$ under cycle of $12 \mathrm{~h}$ of light and $12 \mathrm{~h}$ of darkness. Disease severity and the corresponding level of sporulation for the inoculated leaves were assessed 7 days after inoculation. Disease severity was assessed visually on a per-leaf basis as leaf area (percent) with symptoms. To assess sporulation, leaf discs ( $9 \mathrm{~mm}$ in diameter) were randomly cut from infected leaves and shaken in an Eppendorf tube (two discs per leaf) containing $0.5 \mathrm{ml}$ of $50 \%$ ethanol to dislodge sporangia. The concentration of sporangia in the resultant suspension was then determined using hemocytometer counts. Compatibility reactions were recorded based on sporulation and disease severity as 
described by Cohen et al. (2013) and Thomas et al. (1987) as follows: compatible $(+)=$ approximately $5 \times 10^{3}$ sporangia $/ \mathrm{ml}$ and disease severity $\geq 50 \%$; and incompatible $(-)=$ either low compatibility, with approximately $3 \times 10^{3}$ sporangia/ml and $<20 \%$ disease severity, or no sporulation or infection. Pathotype designation for each isolate was based on compatible or incompatible reaction using a scheme proposed by Thomas et al. (1987) and later expanded by Cohen et al. (2013, 2015).

Data analysis. Associations between the frequency of the two mating types of $P$. cubensis and their original host of isolation and location of the host within the United States were examined using contingency tables and the corresponding number of isolates. First, A1 or A2 mating type isolates were grouped based on presence or absence in the 11 states and presence or absence in northern- or southern-tier states. Northern-tier states comprised Michigan, New Jersey, New York, and Ohio, and southern-tier states included Alabama, Florida, Georgia, North Carolina, South Carolina, and Texas (Ojiambo and Holmes 2011). Second, A1 and A2 mating type isolates were grouped based on whether they were isolated from acorn squash, butternut squash, cantaloupe, cucumber, giant pumpkin, or watermelon. Finally, A1 and A2 mating type isolates were grouped based on whether they were isolated from cucumber or other cucurbits (i.e., acorn and butternut squash, cantaloupe, giant pumpkin, and watermelon). Statistical differences in the distribution of A1 and A2 mating type isolates within these three categories were tested based on Fisher's exact test using PROC FREQ in SAS (version 9.4; SAS Institute).

\section{RESULTS}

Mating type and mating type associations. Pairing of $P$. cubensis isolates with an unknown mating type with either the A1 or A2 tester strain led to production of oospores in the combinations examined. Unknown isolates were either of the A1 or A2 mating type and no self-fertile isolates were observed among isolates collected in this study (Table 1). Of a total of 40 isolates tested, 24 isolates $(60 \%)$ were of the A1 mating type and 16 isolates (40\%) were of the A2 mating type. A1 mating type isolates were all isolated from cucumber, except 2013B17, which was isolated from cantaloupe, and $2013 \mathrm{C} 3$ and $08 \mathrm{C} 1$, that were isolated from giant pumpkin (Table 1). Further, A1 isolates were also recovered from host samples collected in 10 of the 11 states that were part of this study (Table 1). Unlike the A1 isolates, isolates belonging to the A2 mating type were isolated mainly from Cucurbita spp. and C. lanatus but not Cucumis sativus (Table 1). Isolate Pc1982 (collected from cantaloupe in 1987) belonged to the A2 mating type. The A2 mating type isolates were also confined to host samples collected only in Alabama, Florida, Georgia, North Carolina, South Carolina, and Texas (Table 1). Both A1 and A2 mating types of P. cubensis were not isolated from samples of the same cucurbit host, except for cantaloupe (Table 1).

The distribution of isolates belonging to the A1 and A2 mating types within and among states and within and among cucurbit hosts differed within this study (Table 3). For example, the distribution of A1 and A2 isolates was not significantly different within states $(P=0.6178)$. However, significant differences $(P=0.0287)$ in the distribution of the two mating types were observed when states from which samples were collected were classified as in either a northern- or southern-tier state. Isolates belonging to A1 and A2 mating types were present in equal proportions in southern-tier states, whereas all isolates in northern-tier states were A1 (Fig. 1B). Significant differences in the distribution of A1 and A2 isolates were also observed within $(P<0.0001)$ and between $(P<0.0001)$ cucurbit host type (Table 3$)$. Within host types, A1 isolates were exclusively associated with cucumber and giant pumpkin (only two isolates), whereas A2 isolates were exclusively associated with acorn squash, butternut squash, and watermelon (Fig. 1A). Although both A1 and A2 isolates were associated with cantaloupe, the majority of the isolates on cantaloupe were of the A2 mating type (Fig. 1A). When isolate distribution on cucumber was compared with that on other host types, isolates obtained from cucumber were exclusively of the A1 mating type, while the majority of isolates $(84 \%)$ that were obtained from other cucurbits were of the A2 mating type (Fig. 1B).

Oospore production. Coinoculation of unknown isolates of P. cubensis with the A1 or A2 tester strain on detached cantaloupe or cucumber leaves led to production of oospores in pairings involving unknown isolates with the A1 or A2 tester strain. Oospores were produced in detached leaves between 8 and 10 days after pairing unknown isolates with the tester strain. The number of oospores

TABLE 3. Statistics of Fisher's exact test for the differences in the frequency distribution of A1 and A 2 mating types of Pseudoperonospora cubensis among states and cucurbit host type

\begin{tabular}{lrrcc}
\hline Level & df & \multicolumn{1}{c}{$\chi^{2}$} & Prob $<\chi^{2}$ & Prob $<P^{\mathrm{a}}$ \\
\hline State & 10 & 9.7180 & 0.4646 & 0.6178 \\
Northern versus southern states & 1 & 5.9348 & 0.0148 & 0.0287 \\
Host type & 5 & 36.8750 & 0.0001 & 0.0001 \\
Cucumber versus other cucurbits & 1 & 29.4737 & 0.0001 & 0.0001 \\
\hline
\end{tabular}

a Refers to the table probability as calculated by Fisher's exact test.

TABLE 2. Compatibility reaction on a set of cucurbit host differentials following inoculation with a selection of six isolates belonging to different mating types of Pseudoperonospora cubensis

\begin{tabular}{|c|c|c|c|c|c|c|}
\hline \multirow[b]{3}{*}{ Differential host $\mathrm{t}^{\mathrm{b}}$} & \multicolumn{6}{|c|}{ Compatibility reaction by mating type ${ }^{a}$} \\
\hline & \multicolumn{3}{|c|}{ A1 } & \multicolumn{3}{|c|}{ A2 } \\
\hline & $2013 \mathrm{~B} 17$ & 2013A19 & $2013 \mathrm{~A} 18$ & $2013 \mathrm{E} 1$ & $2013 \mathrm{~F} 2$ & 2013D6 \\
\hline Cucumis sativus & $+(48.3)$ & $+(12.3)$ & $+(25.0)$ & $+(7.3)$ & $+(9.5)$ & $+(26.6)$ \\
\hline C. melo reticulatus & $+(6.1)$ & $+(5.5)$ & $+(9.2)$ & $+(23.0)$ & $+(5.3)$ & $+(16.1)$ \\
\hline C. melo conomon & $-(3.0)$ & $+(6.9)$ & $+(13.2)$ & $+(5.1)$ & $+(7.8)$ & $+(25.0)$ \\
\hline Citrullus lanatus & $-(0.0)$ & $-(1.1)$ & $-(0.5)$ & $+(8.4)$ & $+(9.2)$ & $+(3.6)$ \\
\hline Cucurbita spp. & $-(0.0)$ & $-(2.5)$ & $-(0.0)$ & $-(1.4)$ & $+(28.1)$ & $+(25.6)$ \\
\hline Luffa cylindrica & $-(0.6)$ & $-(3.6)$ & $-(4.2)$ & $-(3.7)$ & $-(1.2)$ & $-(0.3)$ \\
\hline Lagenaria siceraria & $-(3.2)$ & $+(6.7)$ & $+(10.6)$ & $-(3.2)$ & $-(1.2)$ & $+(4.0)$ \\
\hline Designated pathotype ${ }^{c}$ & 1 & 3 & 3 & 4 & 5 & 5 \\
\hline
\end{tabular}

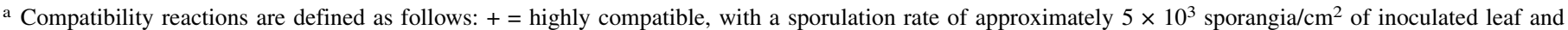
disease severity $\geq 50 \%$; and $-=$ either low compatibility, with a sporulation rate of approximately $3 \times 10^{3}$ sporangia/cm ${ }^{2}$ of inoculated leaf and disease severity $<20 \%$, or very low compatibility, with very sparse sporulation or incompatible reaction with no evidence of sporulation. Values in parenthesis are counts of sporangia $\left(\times 10^{3}\right)$ per square centimeter of inoculated leaf.

b Cucurbita spp. include Cucurbita pepo (acorn squash) and C. moschata (butternut squash).

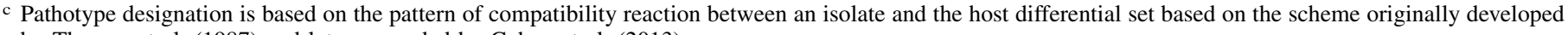
by Thomas et al. (1987) and later expanded by Cohen et al. (2013). 
produced was highly variable and ranged from approximately 280 oospores $/ \mathrm{cm}^{2}$ of leaf tissue for a less-prolific cross between A11 and $2013 \mathrm{~F} 1$ to approximately 1,000 oospores $/ \mathrm{cm}^{2}$ of leaf tissue for a highly prolific cross between A11 and D3 (Table 4). Oospores were hyaline to golden yellow in color and spherical in shape, with thick cell walls composed of two to three layers (Fig. 2). Oospores that were hyaline in color were observed in test crosses conducted on detached cucumber leaves, while golden-yellow oospores were observed when crosses were performed on cantaloupe leaves. The size of oospores was variable and ranged between $24.4 \mu \mathrm{m}$ from the cross between 2013A7 and D3 to $44.6 \mu \mathrm{m}$ from the cross between A11 and 2013F1 (Table 4). The mean diameter of oospores across all crosses evaluated in this study was 33.9 to $38.9 \mu \mathrm{m}$.

Oospore viability. The percentage of oospores that were viable varied among crosses and the method used to assay oospore viability. For example, the most viable oospores were obtained from a cross between 2013A17 and D3 (96.5\%) based on the MTT test, while the cross between A11 and D3 produced the most viable oospores $(59.3 \%)$ using the plasmolysis method (Table 4). In addition, viability based on the MTT test was consistently higher in every cross (67.2 to $96.5 \%)$ than viability estimates based on the plasmolysis method (33.5 to 59.3\%). On average, oospore viability as estimated by the MTT test was approximately 1 to 2.5 times higher than viability estimates based on the plasmolysis method.

Oospore infectivity. Inoculation of cucurbit host types with oospores produced from the crosses evaluated in the study did not result in sporulating lesions on any of the inoculated cucurbit host type even after 21 days after inoculation. After 21 days, leaves of cucurbit host types inoculated with oosporic inoculum started to disintegrate and daily observations for sporulation and formation of sporangia on the lesions were terminated.

Mating type compatibility reaction. Isolates belonging to A1 and A2 mating types differed in their degree of compatibility from the host differential set used in the study (Table 2). A1 isolates
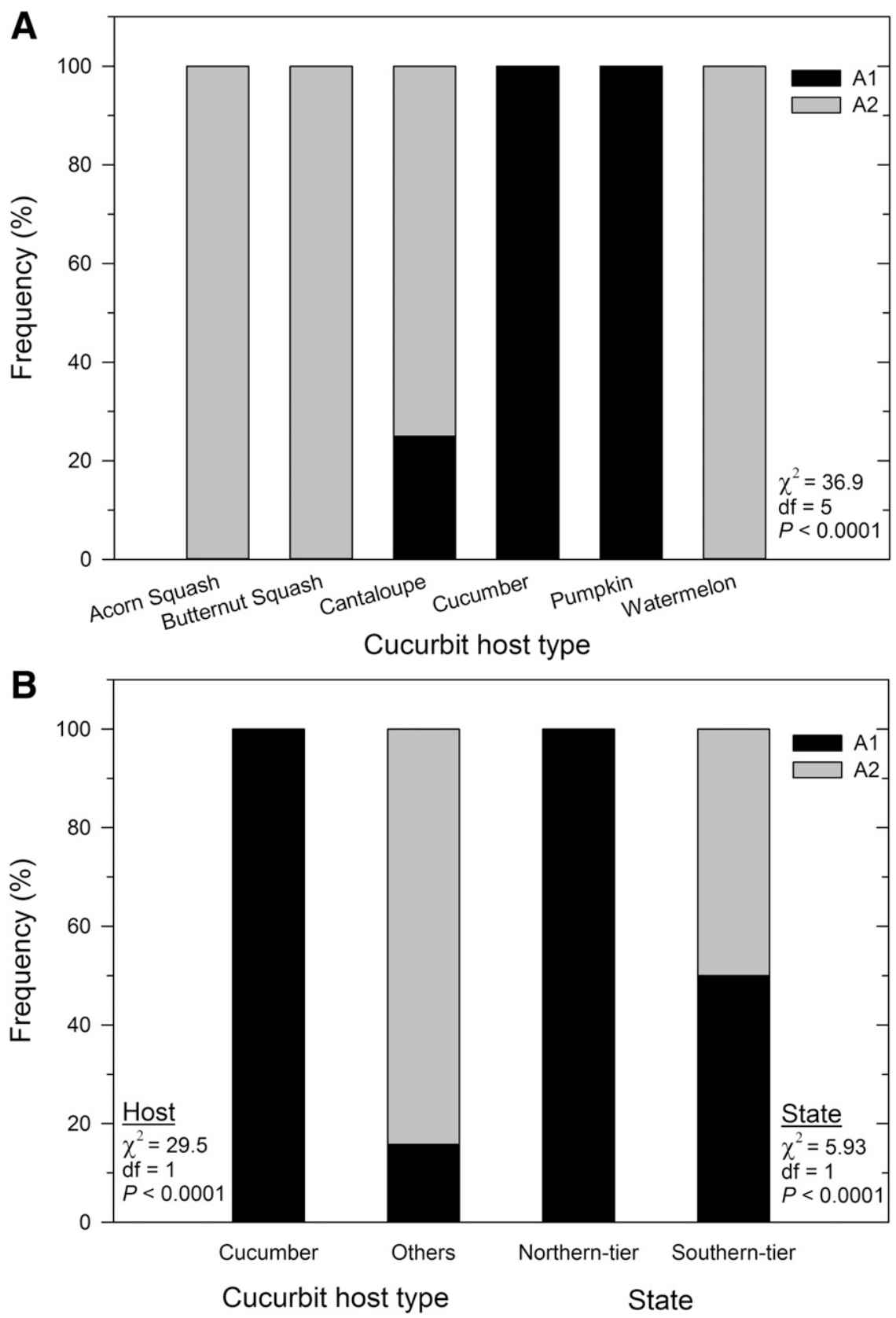

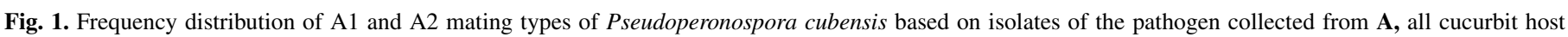

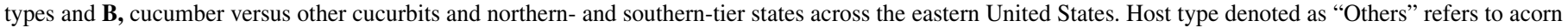
squash, butternut squash, cantaloupe, giant pumpkin, and watermelon. 
were all compatible with $C$. sativus, $C$. melo var. reticulatus, and C. melo var. conomon, except 2013B17, which was not compatible with $C$. melo var. conomon (Table 2). Further, all A1 isolates were also compatible with $L$. siceraria, except 2013B17. Based on their compatibility scheme, A1 isolates were designated as belonging to pathotype 1 (2013B17) and pathotype 3 (2013A18 and 2013A19). Unlike the A1 isolates, isolates belonging to the A2 mating type were all compatible with $C$. sativus, $C$. melo, Citrullus lanatus, and Cucurbita spp., except 2013E1, that was incompatible with Cucurbita spp. (Table 2). Based on their compatibility scheme, isolates belonging to the A2 mating type were designated as belonging to pathotype 4 (2013E1) and pathotype 5 (2013D6 and 2013F2) (Table 2).

\section{DISCUSSION}

This study examined the occurrence and distribution of mating types of $P$. cubensis and the potential of sexual reproduction within the pathogen populations in the United States. It was determined that $\mathrm{A} 1$ and $\mathrm{A} 2$ mating types are present among isolates in the United States. Pairing of isolates belonging to the different mating types resulted in the production of viable oospores, indicating that

TABLE 4. Number, size, and viability of oospores produced on detached leaves of cantaloupe or cucumber in selected crosses between isolates belonging to different mating types of Pseudoperonospora cubensis

\begin{tabular}{|c|c|c|c|c|c|c|}
\hline \multirow[b]{2}{*}{ Cross $(\mathrm{A} 1 \times \mathrm{A} 2)$} & \multirow[b]{2}{*}{ Host substrate } & \multirow[b]{2}{*}{ Oospores (number/cm²) } & \multicolumn{2}{|c|}{ Oospore diameter $(\mu \mathrm{m})$} & \multicolumn{2}{|c|}{ Oospore viability $(\%)^{\mathrm{a}}$} \\
\hline & & & Range & Mean & MTT & Plasmolysis \\
\hline $\mathrm{A} 11 \times \mathrm{D} 3$ & Cantaloupe & 1,004 & $30.6-41.9$ & 37.1 & 76.5 & 59.3 \\
\hline $\mathrm{A} 11 \times 2013 \mathrm{~F} 1$ & Cucumber & 562 & $28.0-44.6$ & 36.4 & 60.1 & 33.4 \\
\hline $08 \mathrm{~A} 1 \times \mathrm{D} 3$ & Cantaloupe & 401 & $30.3-42.6$ & 35.9 & 82.7 & 41.5 \\
\hline $2013 \mathrm{~A} 7 \times \mathrm{D} 3$ & Cucumber & 883 & $24.4-43.3$ & 33.9 & 96.5 & 37.5 \\
\hline $2013 \mathrm{~A} 2 \times \mathrm{D} 3$ & Cantaloupe & 642 & $31.2-42.3$ & 38.3 & 81.8 & 33.5 \\
\hline $2013 \mathrm{~A} 15 \times \mathrm{D} 3$ & Cantaloupe & 281 & $31.6-43.1$ & 38.9 & 88.6 & 37.3 \\
\hline $2013 \mathrm{~A} 10 \times \mathrm{D} 3$ & Cucumber & 602 & $27.7-40.7$ & 34.5 & 73.1 & 44.1 \\
\hline $2013 \mathrm{~A} 17 \times \mathrm{D} 3$ & Cantaloupe & 481 & $29.2-41.1$ & 34.9 & 67.2 & 37.4 \\
\hline Mean & $\ldots$ & 607 & $33.9-38.9$ & 36.2 & 72.5 & 40.5 \\
\hline $\mathrm{SE}^{\mathrm{c}}$ & $\ldots$ & 85 & $\ldots$ & 0.6 & 4.1 & 2.9 \\
\hline
\end{tabular}

${ }^{a}$ MTT denotes the 3-(4,5-dimethylthiazol-2-yl)-2,5-diphenyltetrazolium bromide test.

b Density of oospores was assessed 8 to 10 days after inoculating specific host substrates with inoculum of isolates of the pathogen belonging to different mating types.

c SE denotes the standard error of the mean.

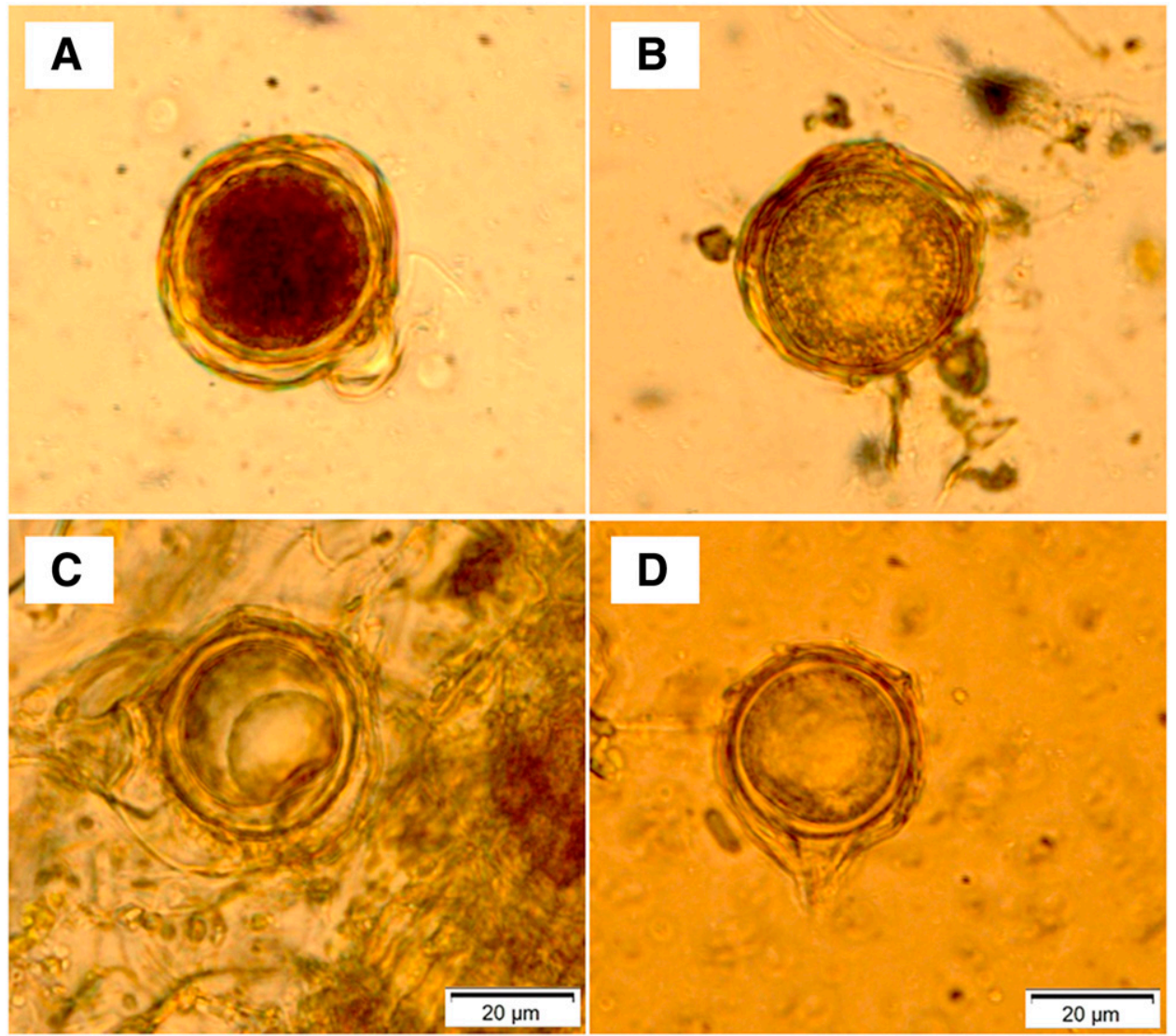

Fig. 2. Viability tests of oospores produced by crossing A1 and A2 mating types of Pseudoperonospora cubensis. Oospores were stained with 0.1\% 3-(4,5dimethylthiazol-2-yl)-2,5-diphenyltetrazolium bromide solution and resulting in A, viable oospores being stained with a bright to deep-red color while B, nonstained oospores are nonviable. Viability was also determined using the plasmolysis method, where $\mathbf{C}$, plasmolysis indicates a viable oospore while $\mathbf{D}$, unplasmolyzed indicates a nonviable oospore. 
the pathogen could sexually reproduce in the United States. As such, $P$. cubensis may now have the potential to overwinter in the field and oospores could serve as an initial source of inoculum in the continental United States. Both mating types were also found to be associated with specific cucurbit host types. This study represents the first documentation of the A1 and A 2 mating types of $P$. cubensis and oospore production in the United States and provides a working framework to examine the role of oospore in the biology and epidemiology of CDM in the United States.

P. cubensis is heterothallic (Cohen and Rubin 2012), and the presence of A1 and A2 mating types and production of oospores is the evidence for the possible existence of a sexually reproducing population. Earlier attempts to detect mating types and oospores of P. cubensis in the United States were not successful (Cohen et al. 2015). This unsuccessful search could partly be explained by limited information at that time on the mating system in P. cubensis and conditions needed for oospore production. In the present study, both mating types were detected among isolates of $P$. cubensis collected across the United States. The A1 isolates were primarily associated with cucumber while the A2 isolates were associated with other cucurbits. Host preference within P. cubensis has also been reported in Israel (Cohen et al. 2013), where A1 isolates showed preference to Cucumis spp. while A2 isolates showed preference to Cucurbita spp. In this study, the two isolates collected from giant pumpkin (Cucurbita maxima) belonged to the A1 mating type, while all isolates from $C$. maxima in the study by Cohen et al. (2013) were of the A2 mating type. In vitro studies indicate that, although both $\mathrm{A} 1$ and $\mathrm{A} 2$ mating type isolates can infect C. maxima, A2 isolates sporulate more on C. maxima than $\mathrm{A} 1$ isolates (A. Thomas and P. S. Ojiambo, unpublished). The mechanism controlling host preference in different mating types of $P$. cubensis is currently unknown. Lebeda et al. (2014) analyzed P. cubensis isolates from some European countries and grouped them based on whether they were collected prior to (clade I) or after (clade II) the change in the virulence in the pathogen population in 2009. It was hypothesized that the A1 mating type was similar to isolates in clade II that had preference to Cucumis spp., while the A2 mating type was similar to isolates in clade I that preferred other cucurbit hosts (Lebeda et al. 2014). Understanding how these clades are associated with different host types may also provide insights into the potential mechanism that controls host preference within P. cubensis.

In this study, only the A1 mating type was found in northern-tier states of New Jersey, New York, Ohio, and Michigan, whereas both A1 and A 2 mating types were present in southern states from Florida to North Carolina. Although this may suggest a possible association of mating type with geographical region, the association between the occurrence of the A1 mating type and northern states was based on a limited number of isolates and did not include isolates from hosts from which only A2 isolates were obtained in the south. A larger sample of isolates from northern-tier states, especially from other host types such as acorn and butternut squash and watermelon, would provide more robust conclusions. Because the resurgence of CDM in the United States was associated with severe losses on cucumber, it is likely that virulent strains of the A1 mating type of $P$. cubensis may have been responsible for the breakdown of the long-standing source of resistance in cucumber from PI 197087. New pathotypes of $P$. cubensis that are aggressive and cause severe epidemics on Cucurbita spp. and Citrullus lanatus have been reported in Czech Republic since 2009 (Kitner et al. 2015). These new pathotypes were associated with an increase in virulence, and most of the isolates belonging to these new pathotypes also contain signatures of sexual recombination (Kitner et al. 2015). Thus, it is possible that a recombinant F1 heterozygote of the A1 mating type that was fit and able to survive and rapidly spread across the eastern states over a relatively short period of time may have been responsible for the resurgence of CDM in the United States.

Oospore production varied among pairings of $P$. cubensis parental isolates where some crosses were prolific and resulted in a high density of oospores. Variation in oospore production can be explained by isolate-specific and combination-specific effects that are analogous to general combining ability and specific combining ability, respectively, reported in genetic studies involving plant and animal breeding (Griffing 1956). Here, isolate-specific effects reflect the average performance of an isolate in parental pairings, while combination-specific effects reflect cases in which certain pairings do relatively better or worse than would be expected on the basis of the average performance of the parent involved. Similar patterns in oospore production have also been reported in $P$. cubensis isolates in Israel (Cohen et al. 2013) and isolates of Phytophthora infestans from Mexico (Flier et al. 2001) and the United Kingdom (Pittis and Shattock 1994). Oospores produced in this study were hyaline to golden-yellow, with a diameter of 24.4 to $44.6 \mu \mathrm{m}$. The size of oospores in the present study is similar to that reported in Japan (Hiura and Kawada 1933) and Israel (Cohen et al. 2013). However, oospores in the present study were much larger than those reported in India, whose diameter was 13.5 to $19.8 \mu \mathrm{m}$ (Bains et al. 1977). Variation in host substrates used for the production of oospores has been suggested as a plausible explanation for differences in oospore size (Cohen et al. 2013). Cucumber was the substrate used in the present study and in studies by Cohen et al. (2013) and Hiura and Kawada (1933), and these three studies had a similar oospore size. However, Melothria maderaspatana was the host substrate in the study by Bains et al. (1977), where oospores were comparatively smaller in size. The oospores in the study of Bains et al. (1977) were observed in intact leaves in the field and not detached leaves, which may also influence oospore size.

The use of germination as an absolute measure of oospore viability is complicated for oomycetes due to dormancy of the oospore. Thus, techniques such as the MTT test and the plasmolysis method have been developed to assess oospore viability to determine their potential role in the biology and epidemiology of plant diseases. In this study, estimates of oospore viability were consistently higher based on the MTT test than the plasmolysis method. Similar observations on high estimates of oospore viability by the MTT test compared with the plasmolysis method have also been reported in other oomycetes (Etxeberria et al. 2011; Flier et al. 2001; Pittis and Shattock 1994). Despite its wide use, the subjectivity in color readings, inconsistency, and existence of false positives has led researchers to conclude that the MTT test is unreliable. However, the plasmolysis method has been reported to be reliable in assessing oospore viability in other oomycetes (Etxeberria et al. 2011; Kunjeti et al. 2016). The plasmolysis method is based on the principle that a cell membrane of a viable cell has differential permeability and the latter is lost for a dead cell. A very high correlation has also been observed between the ability of an oospore to plasmolyze and to germinate after deplasmolysis, further indicating the reliability of the plasmolysis method (Jiang and Erwin 1990). Thus, we can conclude that the percentage of viable of oospores of Pseudoperonospora cubensis in the present study was approximately $40 \%$.

The presence of A 1 and A 2 mating types and production of viable oospores by $P$. cubensis isolates has two important implications on the biology and epidemiology of CDM in the United States. Epidemics of CDM in states that experience winter temperatures below freezing have historically been thought to rely on aerial transport of sporangia from overwintering sources in southern Florida. Our results on oospore production and viability suggest that $P$. cubensis could overwinter in the continental United States and oospores could potentially serve as an initial source of inoculum in states where winter temperatures are below freezing. Because oospores can survive for 10 months and still be infective (Zhang et al. 2012), they could potentially be a source of local initial inoculum in the continental United States from northern Florida to the northeast and Great Lakes region, where the duration between the end of the production period and the next cucurbit season is approximately 10 months. Because our findings were based on in vitro studies, we are unable to directly relate oospore production to 
their ability to cause infection under field conditions. Thus, additional field studies are needed to establish oospore production under natural conditions in the United States. These field studies should involve sampling necrotic tissues of cantaloupe toward the end of the season because both mating types prefer cantaloupe. In addition, sampling fields with cantaloupe planted next to cucumber is likely to increase the detection of oospores under natural field conditions. Sexual recombination can result in new combinations of genes resulting in offspring with adaptation and virulence traits that are different from those of the parents. Recent molecular studies on P. cubensis isolates in Czech Republic (Kitner et al. 2015) before and after the shift in virulence of the pathogen population occurring there in 2009 showed that approximately $67 \%$ of isolates sampled after 2009 had two heterozygous positions in their nrITS sequence, suggestive of sexual reproduction. More direct evidence for the implications of sexual recombination in $P$. cubensis was provided by Cohen et al. (2011), where recombinant progenies exhibited altered sensitivity to metalaxyl and a broadened host range compared with their parents.

Studies conducted by Cohen et al. (2011) showed that $P$. cubensis oospores only formed in the presence of continuous moisture on leaves; however, the role of intermittent moisture on oospore production, germination, and infection of cucurbits is yet to be established. Zhang et al. (2012) reported that oospores were able to survive under natural conditions with temperatures of approximately $-20^{\circ} \mathrm{C}$ and were able to cause infection on inoculated cucumber plants. In this study, inoculation of host types with oosporic inoculum from our crosses did not result in infection. Lack of infection from oosporic inoculum generated from in vitro crosses has also been reported in Phytophthora infestans (Mayton et al. 2000). In the only other study where infection by oosporic inoculum of Pseudoperonospora cubensis from in vitro crosses has been reported (Cohen et al. 2013), the frequency of oosporic infection was $<0.5 \%$, with most of the oospores from the crosses resulting in no infection. This erratic or lack of infection could be related to the dormancy of oospores. In other oomycetes, germination and infection of oospores from in vitro crosses has been observed only when oospores are incubated in the soil for several months at certain temperatures (Mayton et al. 2000) or using specialized media (Rubin and Cohen 2006). However, factors that influence in vitro germination and infection of oospores of $P$. cubensis are still not well understood. In addition, although oospores of $P$. cubensis can overwinter in nature (Zhang et al. 2012), systematic studies are still needed to establish whether they can result in infection under natural conditions. Such studies addressing oospore infection will need to deal with the challenge of ascertaining that oospores in infected leaves are responsible for observed infection, given that vegetative hyphae of isolates of the mating types used to produce oospores are still present in the leaf and are also capable of causing infection.

A compatibility assay based on six isolates showed that A1 isolates belonged to pathotypes 1 and 3 while $\mathrm{A} 2$ isolates belonged to pathotypes 4 and 5. Unlike pathotypes 4 and 5 reported earlier by Thomas et al. (1987), pathotype 1 and 3 isolates had not been previously reported in the United States. All A2 isolates belonged to pathotypes 4 and 5, as was the isolate Pc1982 collected from cantaloupe in 1982. Although this may suggest an association between pathotype and mating type in $P$. cubensis, an additional study using more isolates is needed to generate robust conclusions. A host range study in Michigan (Cespedes-Sanchez et al. 2015) reported that $P$. cubensis was capable of infecting only Cucumis spp. and $L$. siceraria. Because we observed that A1 isolates were capable of causing infection only on Cucumis spp. and L. siceraria, it is likely that isolates in Michigan were of the A1 mating type. Given that pathotype 3 had not previously been reported in the United States and that it was known to be present only in East Asia and Israel, it is plausible that migration of the A1 mating type of P. cubensis, possibly from Israel or East Asia, could have contributed to the resurgence of CDM the United States. Anthropogenic activities have been suggested as potential avenues for the introduction of new pathotypes that may have resulted in the resurgence of CDM in United States and Europe (Runge et al. 2011). The CDM pathogen can be seedborne (Cohen et al. 2014), and global seed trade and exchange of germplasm for resistance breeding could provide opportunities for the migration of strains of $P$. cubensis into new habitats. Regardless of the cause of the resurgence of CDM, P. cubensis in the United States now has the potential for sexual reproduction and the ability to generate diversity within its population. Asexual reproduction in $P$. cubensis will allow for a rapid dissemination of recombinant progenies of the pathogen. This mixed mode of reproduction can facilitate the rapid evolution of the pathogen (McDonald and Linde 2002), leading to a high risk for developing fungicide resistance and less durability of host resistance genes already deployed for the control of CDM.

\section{ACKNOWLEDGMENTS}

This study was supported by Hatch Funds from North Carolina Agricultural Experiment Station for Project Numbers NC02251 and NC02432. We thank collaborators on the CDM ipmPIPE project for their assistance in collecting field samples used in this study; and T. Ghiloni, T. Kolppe, and B. Stevens for assistance with laboratory and greenhouse aspects of this work.

\section{LITERATURE CITED}

Anonymous. 2016. Vegetables Annual Summary. United States Department of Agriculture National Agricultural Statistics Service. Online publication. http://usda.mannlib.cornell.edu/usda/current/VegeSumm/VegeSumm-02-04-2016.pdf

Bains, S. S., Sokhi, S. S., and Jhooty, J. S. 1977. Melothria maderaspatana-A new host of Pseudoperonospora cubensis. Indian J. Mycol. Plant Pathol. 7:86.

Barnes, W. C., and Epps, W. M. 1954. An unreported type of resistance to cucumber downy mildew. Plant Dis. Rep. 38:620.

Bedlan, G. 1989. First evidence for oospores of Pseudoperonospora cubensis (Berk. et Curt.) Rost. on cucumbers grown in greenhouses in Austria. Pflanzenschutzberichte 50:119-120.

Cappelli, C., Buonaurio, R., and Stravato, V. M. 2003. Occurrence of Pseudoperonospora cubensis pathotype 5 on squash in Italy. Plant Dis. 87:449.

Cespedes-Sanchez, M. C., Naegele, R. P., Kousik, C. S., and Hausbeck, M. K. 2015. Field response of cucurbit hosts to Pseudoperonospora cubensis in Michigan. Plant Dis. 99:676-682.

Cohen, Y., Meron, I., Mor, N., and Zuriel, S. 2003. A new pathotype of Pseudoperonospora cubensis causing downy mildew in cucurbits in Israel. Phytoparasitica 31:458-466.

Cohen, Y., and Rubin, A. E. 2012. Mating type and sexual reproduction of Pseudoperonospora cubensis, the downy mildew agent of cucurbits. Eur. J. Plant Pathol. 132:577-592.

Cohen, Y., Rubin, A. E., and Galperin, M. 2011. Formation and infectivity of oospores of Pseudoperonospora cubensis, the causal agent of downy mildew in cucurbits. Plant Dis. 95:874.

Cohen, Y., Rubin, A. E., and Galperin, M. 2013. Host preference of mating type in Pseudoperonospora cubensis, the downy mildew causal agent of cucurbits. Plant Dis. 97:292.

Cohen, Y., Rubin, A. E., Galperin, M., Ploch, S., Runge, F., and Thines, M. 2014. Seed transmission of Pseudoperonospora cubensis. PLoS One 9: e109766.

Cohen, Y., Van den Langenberg, K. M., Wehner, T. C., Ojiambo, P. S., Hausbeck, M., Quesada-Ocampo, L. M., Lebeda, A., Sierotzki, H., and Gisi, U. 2015. Resurgence of Pseudoperonospora cubensis: The causal agent of cucurbit downy mildew. Phytopathology 105:998-1012.

Colucci, S. J. 2008. Host range, fungicide resistance and management of Pseudoperonospora cubensis, causal agent of cucurbit downy mildew. MS thesis, North Carolina State University, Raleigh. Online publication. https:// repository.lib.ncsu.edu/handle/1840.16/2795

Doran, W. L. 1932. Downy mildew of cucumbers. Mass. Agric. Exp. Stn. Bull. No. 283.

Etxeberria, A., Mendarte, S., and Larregla, S. 2011. Determination of viability of Phytophthora capsici oospores with the tetrazolium bromide staining test versus a plasmolysis method. Rev. Iberoam. Micol. 28:43-49.

Flier, W. G., Grünwald, N. J., Fry, W. E., and Turkensteen, L. J. 2001. Formation, production and viability of oospores of Phytophthora infestans from potato and Solanum demissum in the Toluca Valley, central Mexico. Mycol. Res. 105:998-1006. 
Foster, A. C. 1920. The downy mildew of cucurbits caused by Pseudoperonospora cubensis (B. \& C.) Rostow. Thesis, University of Wisconsin, Madison.

Griffing, B. 1956. Concept of general and specific combining ability in relation to diallel crossing systems. Aust. J. Biol. Sci. 9:463-493.

Halsted, B. D. 1889. Peronospora on cucumbers. Bot. Gaz. 14:152-153.

Hiura, M., and Kawada, S. 1933. On the overwintering of Peronoplasmopara cubensis. Jpn. J. Bot. 6:507-513.

Holmes, G. J., Ojiambo, P. S., Hausbeck, M. K., Quesada-Ocampo, L., and Keinath, A. P. 2015. Resurgence of cucurbit downy mildew in the United States: a watershed event for research and extension. Plant Dis. 99: 428-441.

Holmes, G. J., Wehner, T., and Thornton, A. 2006. An old enemy re-emerges. Am. Veg. Grow. 54:14-15.

Jiang, J., and Erwin, D. C. 1990. Morphology, plasmolysis, and tetrazolium bromide stain as criteria for determining viability of Phytophthora infestans. Mycologia 82:107-113.

Kitner, M., Lebeda, A., Sharma, R., Runge, F., Dvořák, P., Tahir, A., Choi, Y.-J., Sedláková, B., and Thines, M. 2015. Coincidence of virulence shifts and population genetic changes of Pseudoperonospora cubensis in the Czech Republic. Plant Pathol. 64:1461-1470.

Kunjeti, S. G., Anchieta, A., Subbarao, K. V., Koike, S. T., and Klosterman, S. J. 2016. Plasmolysis and vital staining reveal viable oospores of Peronospora effusa in spinach seed lots. Plant Dis. 100:59-65.

Lebeda, A. 1992. Screening of wild Cucumis sp. against downy mildew (Pseudoperonospora cubensis) isolates from cucumbers. Phytoparasitica 20:203-210

Lebeda, A., and Cohen, Y. 2011. Cucurbit downy mildew (Pseudoperonospora cubensis) -biology, ecology, epidemiology, host-pathogen interaction and control. Eur. J. Plant Pathol. 129:157-192.

Lebeda, A., Kitner, M., Sedláková, B., Sharma, R., Runge, F., and Thines, M. 2014. Biological and molecular evidences about changes in the host range and virulence of Pseudoperonospora cubensis populations in the Czech Republic. Pages 24-27 in: Cucurbitaceae 2014 Proceedings. M. Havey, Y. Weng, B. Day, and R. Grumet, eds. Michigan State University and University of Wisconsin-Madison, American Society for Horticultural Science, Alexandria, VA.

Lebeda, A., Pavelková, J., Sedláková, B., and Urban, J. 2013. Structure and temporal shifts in virulence of Pseudoperonospora cubensis populations in the Czech Republic. Plant Pathol. 62:336-345.

Lebeda, A., and Urban, J. 2004. Disease impact and pathogenicity variation in Czech populations of Pseudoperonospora cubensis. In: Progress in Cucurbit Genetics and Breeding Research. Pages 267-273 in: Proc. Cucurbitaceae
2004 8th EUCARPIA Meet. Cucurbit Genet. Breed. A. Lebeda and H. S. Paris, eds. Palacký University, Olomouc, Czech Republic.

Mayton, H., Smart, C. D., Moravec, B. C., Mizubuti, E. S. G., Muldoon, A. E., and Fry, W. E. 2000. Oospore survival and pathogenicity of single oospore recombinant progeny from a cross involving US-17 and US-8 genotypes of Phytophthora infestans. Plant Dis. 84:1190-1196.

McDonald, B., and Linde, C. 2002. Pathogen population genetics, evolutionary potential, and durable resistance. Annu. Rev. Phytopathol. 40:349-379.

Ojiambo, P. S., Gent, D. H., Quesada-Ocampo, L. M., Hausbeck, M. K., and Holmes, G. J. 2015. Epidemiology and population biology of Pseudoperonospora cubensis: A model system for management of downy mildews. Annu. Rev. Phytopathol. 53:223-246.

Ojiambo, P. S., and Holmes, G. J. 2011. Spatiotemporal spread of cucurbit downy mildew in the eastern United States. Phytopathology 101:451-61.

Palti, J., and Cohen, Y. 1980. Downy mildew of cucurbits (Pseudoperonospora cubensis): The fungus and its hosts, distribution, epidemiology and control. Phytoparasitica 8:109-147.

Pittis, J. E., and Shattock, R. E. 1994. Viability, germination and infection potential of oospores of Phytophthora infestans. Plant Pathol. 43:387-396.

Quesada-Ocampo, L. M., Granke, L. L., Olsen, J., Gutting, H. C., Runge, F., Thines, M., Lebeda, A., and Hausbeck, M. K. 2012. The genetic structure of Pseudoperonospora cubensis populations. Plant Dis. 96:1459-1470.

Ribeiro, O. K., Gallegly, M. E., and Young, R. J. 1971. Oospore production, viability, and germination in relation to establishment of $\mathrm{F}_{2}$ cultures of Phytophthora infestans. (Abstr.). Phytopathology 61:907.

Rostowzew, S. J. 1903. Beiträge zur Kenntnis der Peronosporeen. Flora (Jena) 92:405-433.

Rubin, E., and Cohen, Y. 2006. An improved method for infecting tomato leaves or seedlings with oospores of Phytophthora infestans used to investigate F1 progeny. Plant Dis. 90:741-749.

Runge, F., Choi, Y., and Thines, M. 2011. Phylogenetic investigations in the genus Pseudoperonospora reveal overlooked species and cryptic diversity in the P. cubensis species cluster. Eur. J. Plant Pathol. 129:135-146.

Sutherland, E. D., and Cohen, S. D. 1983. Evaluation of tetrazolium bromide as a vital stain for fungal oospores. Phytopathology 73:1532-1535.

Thomas, A., Carbone, I., and Ojiambo, P.S. 2013. Occurrence of the A2 mating type of Pseudoperonospora cubensis in the United States. (Abstr.) Phytopathology 103:S2.145.

Thomas, C., Inaba, T., and Cohen, Y. 1987. Physiological specialization in Pseudoperonospora cubensis. Phytopathology 77:1621-1624.

Zhang, Y., Pu, Z., Zhou, X., Liu, D., Dai, L., and Wang, W. 2012. A study on the overwintering of cucumber downy mildew oospores in China. J. Phytopathol. 160:469-474. 